\title{
Respiratory Training Late After Fontan Intervention: Impact on Cardiorespiratory Performance
}

\author{
Lamia Ait Ali $^{1,2} \cdot$ Alessandro Pingitore $^{1}$ (D) Paolo Piaggi $i^{5} \cdot$ Fabio Brucini $^{1} \cdot$ Mirko Passera $^{1} \cdot$ Marco Marotta $^{2}$. \\ Alessandra Cadoni $^{3}$. Claudio Passino $0^{2,4} \cdot$ Giosuè Catapano ${ }^{2} \cdot$ Pierluigi Festa $^{2}$
}

Received: 6 July 2017 / Accepted: 4 January 2018 / Published online: 19 January 2018

(c) Springer Science+Business Media, LLC, part of Springer Nature 2018

\begin{abstract}
Fontan palliation allows patients with "single ventricle" circulation to reach adulthood with an acceptable quality of life, although exercise tolerance is significantly reduced. To assess whether controlled respiratory training (CRT) increases cardiorespiratory performance. 16 Adolescent Fontan patients (age 17. $5 \pm 3.8$ years) were enrolled. Patients were divided into CRT group $(n=10)$ and control group (C group, $n=6$ ). Maximal cardiopulmonary test (CPT) was repeated at the end of CRT in the CRT group and after an average time of 3 months in the $\mathrm{C}$ group. In the CRT group a CPT endurance was also performed before and after CRT. In the CRT group there was a significant improvement in cardiovascular and respiratory response to exercise after CRT. Actually, after accounting for baseline values, the CRT group had decreased breathing respiratory reserve $(-15,95 \% \mathrm{CI}-22.3$ to $-8.0, p=0.001)$ and increased RR peak $(+4.8,95 \% \mathrm{CI} 0.7-8.9, p=0.03)$, VE peak $(+13.7,95 \%$ CI $5.6-21.7, p=0.004), \mathrm{VO}_{2}$ of predicted $(+8.5,95 \% \mathrm{CI} 0.1-17.0, p=0.05), \mathrm{VO}_{2}$ peak $(+4.3,95 \%$ CI 0.3 to $8.2, p=0.04)$, and $\mathrm{VO}_{2}$ workslope $(+1.7,95 \% \mathrm{CI} 0.3-3.1, p=0.02)$ as compared to the control group. Moreover, exercise endurance time increased from 8.45 to $17.7 \mathrm{~min}(p=0.01)$. CRT improves cardiorespiratory performance in post-Fontan patients leading to a better aerobic capacity.
\end{abstract}

Keywords Congenital heart disease $\cdot$ Fontan circulation $\cdot$ Controlled respiratory training $\cdot$ Ergospirometry

\section{Introduction}

The outcome of patients with congenital heart disease (CHD), even functionally single ventricle has improved drastically in the last decades due to improvement in diagnostics, cardiac surgery, and intensive care procedures [1]. The surgical staged treatment of patients with single ventricle, based on the "Fontan circulation" that separates the systemic and pulmonary circulations, with the systemic venous

Alessandro Pingitore

pingi@ifc.cnr.it

1 Clinical Physiology Institute, CNR, Via Moruzzi 1, 56124 Pisa, Italy

2 Fondazione G. Monasterio, Regione Toscana, Pisa, Italy

3 Pediatric Cardiology, Brotzu Hospital, Cagliari, Italy

4 Institute of Life Sciences, Scuola Superiore Sant'Anna, Pisa, Italy

5 National Institute of Diabetes and Digestive and Kidney Disease, National Institutes of Health, Phoenix, AZ, USA return being connected to the pulmonary arteries without the interposition of the right ventricle pump [2]. This surgical intervention allows these patients to reach adulthood with an acceptable quality of life despite a still a non-negligible mortality and morbidity [3]. However, the consequence of these "unnatural" hemodynamics is a limitation of the normal increases in pulmonary pressures and transpulmonary flow, that, in turn, reduces preload reserve and the increase in cardiac output (CO) $[4,5]$. The clinical implication is therefore a reduction in exercise tolerance typical in these patients. Recently a multicentre cohort from the USA Fontan network highlighted the central role of the lungs in postFontan palliation in responding to exercise [6].

Controlled breathing is a method of respiratory training that is a fundamental procedure of Pranayama Yoga and is characterized by conscious slow and deep acts of breathing based on diaphragmatic contraction and relaxation without any kind of instrumentation [7]. The controlled breathing practice provides benefits on well-being in healthy subjects [8] and in patients with different diseases, including heart failure [9-11]. Furthermore, in patients with chronic 
obstructive pulmonary disease diaphragmatic breathing was associated with a significant increase in tidal volume and reduction in breathing frequency, leading to higher ventilation and oxygen saturation, with a reduction in dead space ventilation and ventilatory equivalent for carbon dioxide [12]. The aim of this pilot study was to assess the effect of controlled respiratory training in adolescents post-Fontan palliation patients on exercise tolerance, metabolic capacity, ventilator, and cardiocirculatory response to exercise. We therefore hypothesized that respiratory training increases cardiorespiratory performance in this population through the improvement in ventilation efficiency.

\section{Methods}

\section{Patients}

The enrolled population consisted of 16 adolescent patients post-Fontan palliation (14 males, age 17. $5 \pm 3.8$ years) referred to our outpatient clinic for routine follow-up. This is a tertiary referral center at which patients with CHD are evaluated and followed. Inclusion criteria were: (1) clinical stability (NYHA class I); (2) no diuretic therapy at the enrollment and during the training duration. Patients were divided into 2 groups: group 1: controlled respiratory training (CRT group, $n=10$ ) and group 2 control group (C, $n=6$ ). CRT group and C group had similar demographic, anthropometric, and clinical characteristics as shown in Table 1. Patients enrolled in the CRT group were close to the hospital and this was due to favor their weekly participation to the CRT sessions. Therefore, patients living far from the center entered the $\mathrm{C}$ group. Two patients in the CRT group were subsequently excluded from analysis because of reduced compliance to bicycle exercise, due to mild reduced cerebral development. Data on medical and surgical history, clinical status, peripheral oxygen saturation, NYHA functional class, medical therapy, cardiac magnetic resonance, and echocardiogram were collected and are summarized in Table 1. Medication did not change during the training period. Furthermore, all the enrolled subjects had a low exercise regimen and did not change it during CRT program. All patients underwent baseline spirometry, and single-breath diffusing capacity of the lung for carbon monoxide (DLCO), and incremental cardiopulmonary exercise test (CPET). CPET was repeated at the end of CRT in CRT group and after an average time of 3 months in the $\mathrm{C}$ group. In the 8 patients in the CRT group an endurance test was performed before and after CRT. The research protocol was approved by the local ethics committee review board (Prot 0015-17 2014 P). All patients or legal guardians gave informed consent, and authorized physicians to use their clinical data in accordance with Italian law. All procedures performed in the study were in accordance with the ethical standards of the institutional and/or national research committee and with the 1964 Helsinki declaration and its later amendments or comparable ethical standards.

\section{Controlled Respiratory Training}

CRT consisted of weekly $2 \mathrm{~h}$ sessions, lasting 3 months. This was divided into 2 parts: theoretical and practical. In the theoretical session the educational sessions were the anatomy and physiology of the respiratory system, breathing control and breathing awareness, visualization. The practical part was performed indoors and outside, paying attention to personal comfort and environmental quietness. The first step consisted of teaching the optimal position for correct breathing: sitting in a comfortable position with a straight spine or in the "lotus or "diamant" pose if possible. Patients were encouraged to slowly inhale and bring the air into the bottom of their lungs with the diaphragm, then continue inhaling to open and expand the rib cage upward and finishing inhalation with clavicle respiration. The exhalation time is twice as long as the inhalation time: for example, when an inspiration lasts $4 \mathrm{~s}$, expiration will last $8 \mathrm{~s}$. In the first step the inspiration and expiration were repeated without a break, with nasal inhaling and oral exhaling, in order to control air flux. In the second step both air inhalation and exhalation were accomplished nasally with breaks at maximal inspiration and at maximal expiration. These breaks lasted for $2 \mathrm{~s}$ at the beginning and up to $8 \mathrm{~s}$ at the end of the training. These exercises gave patients a heightened awareness of their breathing thus enabling them to control both frequency and deepness. The control and the awareness of breathing were further enhanced using visualization techniques that are typical in yoga practice with the aim to increase concentration towards breathing. The weekly CRT sessions lasted $2 \mathrm{~h}$ each, for a total number of 14 sessions in the 3 months. Participants were invited to perform CRT exercises at home and were regularly encouraged by their parents and our trainers through mobile-phone messages and/or whatsapp communication.

\section{Lung Function Measurement}

In all the patients evaluated under stable clinical conditions, we obtained pulmonary function tests at baseline. Lung function studies included the spirometry for static and dynamic lung volume measurements: total lung capacity, TLC; slow vital capacity, SVC; forced vital capacity, FVC; and derived indices as forced expiratory volume in the first second and its percentage of vital capacity $\left(\mathrm{FEV}_{1} / \mathrm{VC}\right.$ ratio). Spirometry was performed by experienced technologists. Three spirometric measurements were obtained and the highest values were chosen in conformity with ATS/ERS standards [13]. 
Table 1 Demographic, anthropometric, and clinical characteristics of the two study groups

\begin{tabular}{|c|c|c|c|c|}
\hline & All patients (n: 14) & CRT group (n: 8) & $\mathrm{C}$ group (n: 6) & $p$ \\
\hline Age (years) & $17.5(10.4: 22.8)$ & $17.8(12.8: 22.8)$ & $17.5(10.4: 22.4)$ & 0.51 \\
\hline BMI & $19.7(14.8: 24.5)$ & $18.4(14.8: 21.2)$ & $19.7(15.5: 24.5)$ & 0.43 \\
\hline $\operatorname{BSA}\left(\mathrm{m}^{2}\right)$ & $1.56(1.1: 2.04)$ & $1.56(1.18: 1.68)$ & $1.53(1.1: 2.04)$ & 0.79 \\
\hline Diagnosis & & & & 0.29 \\
\hline $\mathrm{DORV}+\mathrm{PS}+\mathrm{VSD}$ & 1 & 0 & 1 & \\
\hline $\mathrm{TGA}+\mathrm{VSD}$ & 1 & 1 & 0 & \\
\hline DILV & 4 & 3 & 1 & \\
\hline HLHS & 2 & 1 & 1 & \\
\hline Mitral atresia-VSD & 2 & 0 & 2 & \\
\hline PAIVS & 1 & 0 & 1 & \\
\hline Tricuspid atresia & 2 & 2 & 0 & \\
\hline Ventricle type & & & & 0.24 \\
\hline Two complex ventricles & 2 & 1 & 1 & \\
\hline Right ventricle & 6 & 2 & 3 & \\
\hline Left ventricle & 6 & 5 & 2 & \\
\hline Age at Fontan (years) & $3.96(0.8: 7.4)$ & $3.6(0.8: 7.4)$ & $4.2(3.2: 4.7)$ & 0.69 \\
\hline Follow-up from Fontan & $13.7(6: 19.3)$ & $14.1(9.5: 19.3)$ & $13.4(6: 19.2)$ & 0.5 \\
\hline Fontan type & & & & 0.69 \\
\hline Extracardiac conduit & 10 & 5 & 5 & \\
\hline Intracardiac conduit & 1 & 1 & 0 & \\
\hline Intracardiac tunnel & 2 & 1 & 1 & \\
\hline Kawashima & 1 & 1 & 0 & \\
\hline Peripheral $\mathrm{O}_{2}$ Sat $(\%)$ & 95 (88: 99) & 95.5 (90: 99) & 95 (88: 97) & 0.33 \\
\hline Cardiac index $\left(1 / \mathrm{min} / \mathrm{m}^{2}\right)$ & $3.1(2.2: 3.7)$ & $3.1(2.2: 3.7)$ & $3.1(2.7: 3.5)$ & 0.99 \\
\hline Ventricle EDVI $\left(\mathrm{ml} / \mathrm{m}^{2}\right)$ & $101(58: 164)$ & 93 (67: 164) & $120(58: 162)$ & 0.62 \\
\hline Ventricle EF (\%) & $47(29: 68)$ & 49 (29: 68) & $42(37: 54)$ & 0.33 \\
\hline $\begin{array}{l}\text { Moderate systemic AV valve } \\
\text { regurgitation }{ }^{\mathrm{a}}\end{array}$ & $6(43 \%)$ & $4(50 \%)$ & $1(17 \%)$ & 0.21 \\
\hline
\end{tabular}

$A V$ atrioventricular, $B M I$ Body Mass Index, BSA body surface area, $C$ Group control group, $C R T$ controlled respiratory training, $D I L V$ double inlet left ventricle, $D O R V$ double outlet right ventricle, $E F$ ejection fraction, EDVI end-diastolic volumes indexed, HLHS hypoplastic left heart syndrome, PAIVS pulmonary atresia intact ventricular septum, $P S$ pulmonary stenosis, $T G A$ transposition of great arteries, VSD ventricular septal defect

${ }^{\mathrm{a}}$ Moderate: more than trivial, no patient have a severe $\mathrm{AV}$ valve regurgitation
Airway obstruction was considered for a ratio of FEV1/SVC below the 5 th percentile of predicted value (less than $88 \%$ of predicted value), and ventilatory restriction if FEV1/SVC ratio was normal for a TLC below the 5th percentile of predicted less than $80 \%$ of predicted value [14]. DLCO was determined using the single-breath method in conformity with ATS/ERS recommendations [15]. Alveolar volume was measured during the single-breath maneuver using helium as the inert gas. Carbon monoxide transfer coefficient was also evaluated, expressed as the ratio between DLCO and alveolar volume (DLCO/VA) as a percentage of the predicted value. Both DLCO and the DLCO/AV ratio were considered abnormal for values $80 \%$ lower than the predicted value. Maximal Voluntary Ventilation (MVV) was estimated multiplying $\mathrm{FEV}_{1}$ value by a correction factor of 40 [16]. Lung function tests were obtained in the same day of CPET.

\section{CardioPulmonary Exercise Test (CPET) Before and After Respiratory Training}

CPET was performed on an electrically braked cycle ergometer (Ergostik, Geratherm, Germany) in accordance with ATS/ACCP recommendations [17]. The protocol included three stages: resting, unloaded pedaling, and exercise. The external work rate was incremented continuously using the ramp protocol and the patients were encouraged to cycle until exhaustion (maximal exercise symptom-limited). The patients were asked to specify the reason(s) why they stopped exercising. During the test, the electrocardiogram was monitored by telemetry, and the arterial oxygen saturation measured by pulse oximetry (SpO2). The test was interrupted if any of the following events occurred: signs of ischemia on the 
electrocardiogram, hypertension (systolic blood pressure $220 \mathrm{mmHg}$ or diastolic blood pressure $120 \mathrm{mmHg}$ ), second or third degree heart block, or severe desaturation $(\mathrm{SpO} 2$ B $80 \%$ ). Ergospirometry test was used for assessing the physical performance outcomes of ventilatory, cardiovascular, and metabolic response to maximal exercise.

The following variables were measured at peak exercise through breath by breath analysis of inhaled and exhaled gases: Oxygen uptake $\left(\mathrm{VO}_{2}\right)$, and its relationship with heart rate and external work (pulse oxygen or $\mathrm{VO}_{2} / \mathrm{HR}$ and $\mathrm{VO}_{2}$ /Work slope); $\mathrm{CO}_{2}$ production $\left(\mathrm{VCO}_{2}\right)$ and gas ventilatory equivalents $\left(\mathrm{VEVO}_{2}, \mathrm{VEVCO}_{2}\right)$; the physiological dead space to the tidal volume ratio $\left(V_{\mathrm{d}} / V_{\mathrm{t}}\right)$, and tidal volume to slow vital capacity ratio $\left(\mathrm{V}_{\mathrm{T}} / \mathrm{SVC}\right)$; minute ventilation expressed as the highest value recorded either during exercise or at the first time recovery phase $\left(\mathrm{VE}_{\text {peak }}\right)$; breathing respiratory reserve (BRR, expressed as the difference in liters between MVV and $\mathrm{VE}_{\text {peak }}$ ). The anaerobic threshold (AT) was estimated by V slope method and ventilatory equivalent method [17]. Maximal exercise capacity was expressed as external work rate achieved (W), and peak oxygen uptake normalized for the body surface area $\left(\mathrm{VO}_{2 \text { peak }} \mathrm{ml} / \mathrm{min} / \mathrm{kg}\right)$ on the modified Weber and Janicki scale. The endurance test was performed before and after training only for CRT group. The test was performed based on the $80 \%$ workload reached in maximal CPET, and aerobic endurance derived from the effective measure of the exercise time in minutes and the anaerobic threshold achieved.

\section{Statistical Analysis}

Continuous variables normally distributed by the Shapiro-Wilk normality test were presented as means \pm SD or mean with its $95 \%$ confidence interval (CI), as indicated. Continuous variables with skewed distribution were presented as median and as median and range. Categorical variables were presented as counts and percentages. The Student's unpaired $t$ test was used to compare values of normally distributed variables between the CRT group and the control group at baseline. The Mann-Whitney U test was used for variables with skewed distributions. Withingroup changes were evaluated by the Wilcoxon test. As the assumption of Gaussian distribution may not be valid in our relatively small sample size, non-parametric analyses were always performed to confirm results obtained by parametric tests. Changes in each spirometry and maximal cardiopulmonary test parameter between the two groups were evaluated by analysis of covariance (ANCOVA) accounting for baseline values. A $p$ value $<0.05$ was considered statistically significant. All analyses were performed using SPSS (version 21.0).

\section{Results}

\section{Baseline Results}

The population study consisted in 14 patients ( 2 females), age: $17.5(10.4 ; 22.8)$ years. The most frequent diagnosis was double inlet ventricle and single ventricle morphology was more likely left. The Fontan operation, was performed at median age of $3.96(0.8 ; 7.4)$ years, most frequently with an extracardiac conduit. Six patients underwent a fenestrated Fontan but the fenestration was yet patent at the time of the study in only 3 patients. The parameters of spirometry at rest and ergospirometry performed before training were similar between the two groups, although C group had a slightly better, but not significant, lung function and metabolic capacity to exercise (Table 2). A restrictive pattern was found in $6 / 14$ patients (43\%); there were no differences in the prevalence of restrictive pattern between the CRT group and the $\mathrm{C}$ group (Table 2). $\mathrm{VO}_{2 \text { peak }}$ was low in both groups indicating a deconditioned level to exercise. There were no significant differences in weightnormalized and percent-predicted $\mathrm{VO}_{2 \text { peak }}$ between the two groups as well as global ventricular function.

\section{Exercise Program Adherence}

During all the CRT period, patients were clinically stable and did not need of any kind of therapeutic or medical intervention. The number of the training sessions over 3 months were 14 . Median adherence to CRT was 11 , range 6-14. All subjects performed training at home with a frequency of $4 \pm 1.5 \mathrm{~h}$ a week.

\section{Effect of Respiratory Training on CardioRespiratory Response to Exercise}

After accounting for baseline values, on average the CRT group had decreased breathing respiratory reserve $(-15$, 95\% CI -22.3 to $-8.0, p=0.001)$ and increased RR peak $(+4.8,95 \%$ CI $0.7-8.9, p=0.03)$, VE peak $(+13.7,95 \%$ CI 5.6-21.7, $p=0.004), \mathrm{VO}_{2}$ of predicted $(+8.5,95 \% \mathrm{CI}$ $0.1-17.0, p=0.05), \mathrm{VO}_{2}$ peak $(+4.3,95 \%$ CI $0.3-8.2$, $p=0.04)$, and $\mathrm{VO}_{2}$ workslope $(+1.7,95 \%$ CI $0.3-3.1$, $p=0.02)$ as compared to the control group.

All the CPT parameters are reported in Table 3. Significant changes occurring after CRT are reassumed in the following points: 
Table 2 Spirometry and maximal cardiopulmonary test characteristics of the two groups

\begin{tabular}{|c|c|c|c|}
\hline & CRT group & Control group & $p$ \\
\hline TLC (\% of predicted) & $75.5(53 ; 125)$ & $100(65 ; 111)$ & 0.5 \\
\hline FEV1 ( $\%$ of predicted) & $72(46 ; 114)$ & $96.5(58 ; 121)$ & 0.2 \\
\hline FEV1/VC (\% of predicted) & $103(82 ; 115)$ & $99.6(77 ; 108)$ & 0.3 \\
\hline MVV & $110.8(60.8 ; 154.8)$ & $141(53 ; 175)$ & 0.4 \\
\hline TLCO (\% of predicted) & $59(36 ; 101)$ & $60(45 ; 83)$ & 0.6 \\
\hline Obstructive pattern $N(\%)$ & $1(12 \%)$ & $0(0 \%)$ & 0.4 \\
\hline Restrictive pattern $N(\%)$ & $4(50 \%)$ & $2(33 \%)$ & 0.72 \\
\hline Max workload (W) & $89.5(54 ; 135)$ & $103(56 ; 138)$ & 0.4 \\
\hline $\mathrm{VO}_{2 \text { peak }}(\mathrm{ml} / \mathrm{kg} / \mathrm{min})$ & $21.3(18.6 ; 32.9)$ & $28(14.1 ; 32.6)$ & 0.34 \\
\hline $\mathrm{VO}_{2}(\%$ of predicted $)$ & $45.5(37 ; 70)$ & $57.5(29 ; 86)$ & 0.33 \\
\hline HR rest (BPM) & $96(77 ; 116)$ & $76(60 ; 111)$ & 0.15 \\
\hline HR peak (BPM) & $141.5(103 ; 170)$ & $145(132 ; 172)$ & 0.5 \\
\hline HR peak ( $\%$ of predicted) & $71.5(51 ; 85)$ & $72(67 ; 82)$ & 0.47 \\
\hline $\mathrm{RR}$ (rest) & $19.5(14 ; 26)$ & $18.5(14 ; 22)$ & 0.13 \\
\hline RR (peak) & $36(33 ; 49)$ & $33.5(29 ; 38)$ & 0.15 \\
\hline Oxygen pulse $\left(\mathrm{VO}_{2} / \mathrm{HR}\right)$ (peak) & $8(5.8 ; 14.5)$ & $9.4(5.5 ; 13.9)$ & 0.7 \\
\hline $\mathrm{VO}_{2} /$ Work slope & $9.25(4.5 ; 13.6)$ & $10.6(8.7 ; 12.2)$ & 0.33 \\
\hline $\mathrm{VE}_{\text {peak }}(1 / \mathrm{min})$ & $36(30 ; 72)$ & $56.5(33 ; 76)$ & 0.13 \\
\hline $\mathrm{VE} / \mathrm{CO}_{2}$ slope & $34.3(24.8 ; 38)$ & $32(29 ; 44)$ & 0.79 \\
\hline VT rest (1/min) & $0.5(0.3 ; 0.69)$ & $0.54(0.33 ; 0.78)$ & 0.3 \\
\hline VT peak (1/min) & $1(0.78 ; 1,56)$ & $1.68(0.86 ; 2.3)$ & 0.06 \\
\hline$V_{\mathrm{d}} / V_{\mathrm{t}}$ peak & $0.12(0.1 ; 0.15)$ & $0.12(0.09 ; 0.15)$ & 0.8 \\
\hline Breathing respiratory reserve ( $1 / \mathrm{min})$ & $66.5(21.8 ; 101)$ & $79.7(20.2 ; 112)$ & 0.79 \\
\hline
\end{tabular}

$C R T$ controlled respiratory training, $H R$ heart rate, $F E V 1$ forced expiratory volume in $1 \mathrm{~s}, M V V$ maximal voluntary ventilation, $T L C$ total lung capacity, $T L C O$ alveolar-capillary lung transfer of monoxide carbonique, $R R$ respiratory rate, $V E$ minute ventilation, $V \mathrm{O}_{2}$ peak $\mathrm{O}_{2}$ consumption, $V T$ tidal volume
(1) Improvement in metabolic capacity as shown by a significant increase in both weight-normalized and percent-predicted peak $\mathrm{VO}_{2}$ (Table 3).

(2) Improvement in ventilatory response to exercise, as demonstrated by a significant increase in peak VE and lower BRR, and also the tendency of VT to increase, although it was not statistically significant.

(3) Improvement in cardiocirculatory response, as shown by the lower resting heart rate, and the increase in $\mathrm{VO}_{2} /$ work slope (Table 3).

Moreover, these improvements occurred in absence of ventilation/perfusion mismatching, as shown by similar values of $\mathrm{VE} / \mathrm{VCO}_{2}$ slope and physiological dead space-tidal volume ratio $\left(V_{\mathrm{d}} / V_{\mathrm{t}}\right)$ before and after CRT (Table 3).

At rest, four patients in the CRT group and two patients in the $\mathrm{C}$ group reached the anaerobic threshold, whereas none reached anaerobic threshold after CRT in the CRT group. Due to the small number of cases, statistical analysis was not performed. At endurance test the time duration of exercise increased significantly at the same aerobic capacity reached expressed as ratio time endurance $/ \mathrm{VO}_{2} / \mathrm{kg} / \mathrm{min}$ (Fig. 1a, b).
In the $\mathrm{C}$ group there were no significant differences on respiratory, cardiovascular and metabolic response parameters between the 2 maximal CPT performed within the 3 months' time interval (Table 4). Peripheral baseline arterial oxygen saturation didn't change significantly after CRT training in CRT groups: $95.5(90 ; 99)$ pre- training versus $98(85 ; 100), p=1)$. Furthermore, there was no association between the number of the training sessions with the percentage of improvement of cardiorespiratory, metabolic and respiratory parameters, in part due to the limited statistical power to detect a significant correlation in this sample.

\section{Discussion}

The main results of this pilot study showed that adolescents patients who underwent Fontan surgical interventions had a significantly improved $\mathrm{VO}_{2}$ peak and, more importantly, endurance time after dedicated CRT. This is the first time that CRT has been used in this population, in which there is a compromised pulmonary function, mainly due to a restrictive pattern, as we confirmed, and a low functional capacity as indicated by baseline low peak $\mathrm{VO}_{2}$. In addition 
Table 3 Maximal cardiopulmonary exercise test data before and after CRT in the CRT group

\begin{tabular}{|c|c|c|c|}
\hline & Before CRT & After CRT & $p$ \\
\hline Max workload (W) & $89.5(54 ; 135)$ & $93(70 ; 150)$ & 0.06 \\
\hline $\mathrm{VO}_{2 \text { peak }}(\mathrm{ml} / \mathrm{kg} / \mathrm{min})$ & $21.3(18.6 ; 32.9)$ & $27.8(20.5 ; 32.2)$ & 0.02 \\
\hline $\mathrm{VO}_{2}(\%$ of predicted $)$ & $45.5(37 ; 70)$ & $61(45 ; 68)$ & $\mathbf{0 . 0 3}$ \\
\hline $\mathrm{HR}$ rest $(\mathrm{B} / \mathrm{min})$ & $96(77 ; 116)$ & $87(73 ; 103)$ & 0.01 \\
\hline HR peak $(B / m i n)$ & $141.5(103 ; 170)$ & $139(114 ; 160)$ & 0.73 \\
\hline HR peak (\% of predicted) & $71.5(51 ; 85)$ & $70(56 ; 80)$ & 0.46 \\
\hline HR reserve (peak-rest HR) & $38(15 ; 68)$ & $51(32 ; 66)$ & 0.3 \\
\hline $\mathrm{RR}$ at rest $(\mathrm{Br} / \mathrm{min})$ & $19.5(14 ; 26)$ & $17(16 ; 27)$ & 0.44 \\
\hline $\mathrm{RR}$ at peak (Br/min) & $36(33 ; 49)$ & $43(36 ; 46)$ & 0.01 \\
\hline Oxygen pulse $\left(\mathrm{VO}_{2} / \mathrm{HR}\right)$ (peak) & $8.1(5.9 ; 14.5)$ & $9.3(7 ; 16.6)$ & 0.1 \\
\hline $\mathrm{VO}_{2} /$ work slope & $9.25(4.5 ; 13.6)$ & $11.2(9.3: 13.5)$ & 0.02 \\
\hline $\mathrm{VE}_{\text {peak }}(1 / \mathrm{min})$ & $36(30 ; 72)$ & $52(42 ; 88)$ & 0.01 \\
\hline $\mathrm{VE} / \mathrm{VCO}_{2}$ slope & $34.3(24.8 ; 38)$ & $33.9(25 ; 40.9)$ & 0.6 \\
\hline $\mathrm{VE} / \mathrm{VO}_{2}$ (rest) & $30.6(25 ; 42.8)$ & $28.8(24.3 ; 38.8)$ & 0.2 \\
\hline $\mathrm{VE} / \mathrm{VO}_{2}$ (peak) & $30.9(27.5 ; 38.8)$ & $38.1(28.6 ; 38)$ & 0.01 \\
\hline VT rest $(1 / \mathrm{min})$ & $0.5(0.3 ; 0.69)$ & $0.49(0.26 ; 0.67)$ & 0.5 \\
\hline VT peak (1/min) & $1(0.78 ; 1.56)$ & $1.32(0.97 ; 1.93)$ & 0.07 \\
\hline$V_{\mathrm{d}} / V_{\mathrm{t}}$ peak & $0.12(0.1 ; 0.15)$ & $0.13(0.11 ; 0.17)$ & 0.25 \\
\hline Breathing respiratory reserve $(1 / \mathrm{min})$ & $66.5(21.8 ; 101)$ & $62(28.4 ; 92.8)$ & 0.06 \\
\hline
\end{tabular}

Significant results are indicated in bold

$\mathrm{B} / \mathrm{min}$ beat/min, $\mathrm{Br} / \mathrm{min}$ breath/min, $C R T$ controlled respiratory training, $H R$ heart rate, $F E V 1$ forced expiratory volume in $1 \mathrm{~s}, M V V$ maximal voluntary ventilation, $T L C$ total lung capacity, $R R$ respiratory rate, $V E$ minute ventilation, $V \mathrm{O}_{2}$ peak $\mathrm{O}_{2}$ consumption, $V T$ tidal volume (a)

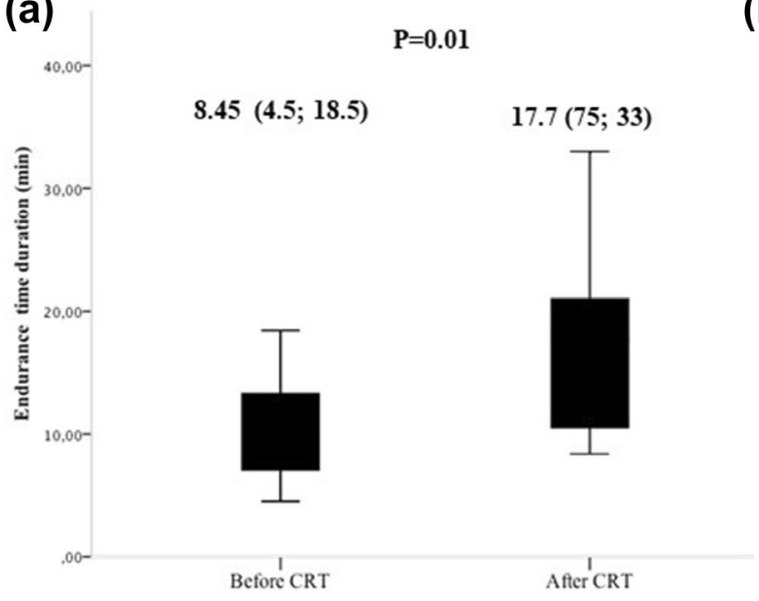

(b)

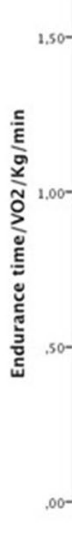

$\mathrm{P}=\mathbf{0 . 0 1}$

$0.35(0.19 ; 0.88) \quad 0.81(0.23 ; 1.46)$
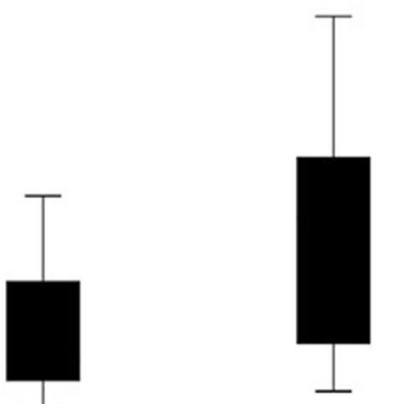

Aréćcr

Fig. 1 Box-plot diagram illustrated an increasing of exercise time after respiratory training at endurance cardiopulmonary test. Values are expressed in median and range. CRT controlled respiratory training

to the respiratory training proposed in this study, respiratory muscle training, in particular the inspiratory one, has been applied in patients with several pulmonary diseases, like COPD and asthma. This provided benefits in improving pulmonary function, endurance, exercise capacity, alleviating symptoms, and thus improving quality of life [18-20]. Respiratory muscle training was also beneficial in patients with cardiac diseases as in those with heart failure and atrial fibrillation $[21,22]$. Particularly in patients with heart failure, respiratory muscle training improved peak $\mathrm{VO}_{2}$, walking distance, quality of life and reduced perceived dyspnea and resting heart rate [19]. Respiratory muscle training is usually performed with an instrument that provokes a resistance against which patients have to breath, inducing increase 
Table 4 Maximal cardiopulmonary exercise test data in control group

\begin{tabular}{|c|c|c|c|}
\hline & $1^{\circ} \mathrm{CPT}$ & $2^{\circ} \mathrm{CPT}$ & $p$ \\
\hline Max workload & $103(56 ; 138)$ & $115(63 ; 132)$ & 0.22 \\
\hline $\mathrm{VO}_{2 \text { peak }}(\mathrm{ml} / \mathrm{kg} / \mathrm{min})$ & $28(14.1 ; 32.6)$ & $27.3(14 ; 30)$ & 0.13 \\
\hline $\mathrm{VO}_{2}(\%$ of predicted $)$ & $57.5(29 ; 86)$ & $56.5(30 ; 81)$ & 0.23 \\
\hline $\mathrm{O}_{2}$ sat $(\%)$ at rest & $91.5(86 ; 97)$ & $92(86 ; 97)$ & 1 \\
\hline HR rest & $76(60 ; 111)$ & $78(73 ; 106)$ & 0.89 \\
\hline HR peak & $145(132 ; 172)$ & $140(118 ; 180)$ & 0.28 \\
\hline HR peak ( $\%$ of predicted) & $72(67 ; 82)$ & $71(59 ; 86)$ & 0.34 \\
\hline HR reserve (peak-rest HR) & $68(39 ; 95)$ & $58.5(39 ; 107)$ & 0.46 \\
\hline $\mathrm{RR}$ at rest & $18.5(14 ; 22)$ & $17.5(10 ; 29)$ & 0.5 \\
\hline $\mathrm{RR}$ at peak & $33.5(29 ; 38)$ & $35(32 ; 38)$ & 0.46 \\
\hline Oxygen pulse $\left(\mathrm{VO}_{2} / \mathrm{HR}\right)$ (peak) & $9.4(5.5 ; 13.9)$ & $9.95(5.7 ; 12.8)$ & 0.89 \\
\hline $\mathrm{VO}_{2} /$ Work slope & $10.6(8.7 ; 12.2)$ & $10.45(8.3 ; 12)$ & 0.68 \\
\hline $\mathrm{VE}_{\text {peak }}(1 / \mathrm{min})$ & $56.5(33 ; 76)$ & $61(32 ; 64)$ & 0.89 \\
\hline $\mathrm{VE} / \mathrm{CO}_{2}$ slope & $32(29 ; 44)$ & $33(29 ; 52.7)$ & 0.08 \\
\hline VT rest (1/min) & $0.54(0.33 ; 0.78)$ & $0.54(0.36 ; 0.87)$ & 0.89 \\
\hline VT peak (1/min) & $1.68(0.86 ; 2.3)$ & $1.69(0.88 ; 1.9)$ & 0.22 \\
\hline$V_{\mathrm{d}} / V_{\mathrm{t}}$ peak & $0.12(0.09 ; 0.15)$ & $0.1(0.09 ; 0.12)$ & 0.46 \\
\hline Breathing respiratory reserve $(1 / \mathrm{min})$ & $79.7(20.2 ; 112)$ & $77.9(21.2 ; 112)$ & 0.89 \\
\hline
\end{tabular}

$H R$ heart rate; $F E V 1$ forced expiratory volume in $1 \mathrm{~s}, M V V$ maximal voluntary ventilation, $T L C$ total lung capacity, $R R$ respiratory rate, $R T$ respiratory training, $V E$ minute ventilation, $V O_{2}$ peak $\mathrm{O}_{2}$ consumption, $V T$ tidal volume in inspiratory, and also expiratory, pressure, and thus favoring respiratory muscle contraction. However, the efficacy of respiratory muscle training depends on different factors including the level of inspiratory pressure load, rhythm, muscle shortening speed that may account for the discrepancies in the true effectiveness in clinics [23, 24]. Furthermore, fragile patients could not support forced breathing with the consequence that the effectiveness of breathing exercise may lower. In experimental settings, moreover, resistive breathing was associated to muscle membrane and sarcomere injury of the diaphragm very likely induced by overproduction of free radicals $[25,26]$.

We, instead, adopted a method of respiratory training based on diaphragmatic respiration, that is natural, unforced, and without instruments. Diaphragmatic respiration increases inspiratory act deepness that augments negative intrathoracic pressure favoring systemic venous return through a suction mechanism. Previous studies showed that spontaneous inspiration as well as negative pressure ventilation increased pulmonary blood flow in early postoperative Fontan patients [27-29]. Penny et al. showed that normal inspiration was associated to $35 \%$ higher pulmonary forward flow during inspiration in respect to expiration in Fontan patients [27-29]. Similarly, in the same category of patients, a significant increase of $42 \%$ in pulmonary blood flow induced by negative pressure ventilation has been shown in the early postoperative period [29]. Importantly, in another study the increase in pulmonary blood flow has been associated to improvement in mixed venous saturation, and improvement in stroke volume and $\mathrm{CO}$ without changes in heart rate [28]. Accordingly, in our study, there was an improvement in respiratory performance as documented in the improvement in ventilatory capacity, as documented by increase in VE peak and larger use of BRR, and also in cardiac performance, as documented by reduction in resting $\mathrm{HR}$ and increase in $\mathrm{VO}_{2}$ /work slope ratio. Thus, in turn, the improvement in cardiorespiratory performance led to significant increase in $\mathrm{VO}_{2}$ max.

The increase in pulmonary blood flow and also the improvement in ventilatory performance have important physiological and clinical impact in Fontan patients considering the abnormal hemodynamics of the systemic venous blood return to the pulmonary circulation. In fact, systemic venous blood flows passively through the lungs without being pumped by the right ventricle and its return is possible by the existence of an elevated central venous pressure which is the driving force in the Fontan circulation [30]. Therefore, patients with Fontan circulation typically have a reduction in $\mathrm{CO}$ at rest and low ability to boost $\mathrm{CO}$ during exercise [30-32]. Cardiac output is the result of the combination of several left ventricle factors including cardiac preload and afterload, contractility, heart rate, as well as right ventricular function and pulmonary circulation [30]. In Fontan patients the increased systemic venous pressure, the absence of the RV pump, and the increased pulmonary vascular resistance, limits or fully abolish preload reserve [4, 
33]. In these patients the increase in $\mathrm{CO}$ was related only to augmentation of heart rate in the presence of decreased LV diastolic volume whereas preload reserve was low at low dose dobutamine stress test [34]. Dobutamine also showed abnormal pulmonary artery distensibility and wall shear stress suggesting endothelial dysfunction [35]. Interestingly the administration of a single oral dose of sildenafil, a pulmonary vasodilator, increased cardiac index, and exercise capacity in association with the increase in pulmonary blood flow [36]. The key role of the pulmonary system in the hemodynamics of Fontan patients derives from recent evidence showing that a low FVC is predictive of a low peak $\mathrm{VO}_{2}$ and that this association is stronger than that seen for ventricular morphology or markers of ventricular dysfunction [6]. Moreover, Shafer et al. demonstrate that the skeletal muscle and ventilatory pumps account entirely for the increase in SV during submaximal exercise in patients with Fontan circulation [37]. The increase in endurance time furthermore, occurred at the same aerobic capacity as expressed by the time endurance $/ \mathrm{VO}_{2} / \mathrm{kg} / \mathrm{min}$ ratio in respect to pre-training, thus indicating an improved cardiorespiratory efficiency. The observed improvement in functional capacity indicates the presence of a functional cardiorespiratory reserve that can be pulled out in order to improve exercise capacity. This is in line with recent evidence showing the efficiency of exercise aerobic training in Fontan patients and the results of a recent published meta-analysis of Sutherland et al. who concluded that exercise training is safe and beneficial in patients with a Fontan circulation and should become standard care within this population [5, 38-43]. Moreover, the increase in exercise performance is also effective to improve quality of life helping to reduce the rate of depression and anxiety, that are frequent in the Fontan population [44].

In addition, CRT may induce directly benefit by favoring relaxation, reduction in perceived exertion, physical and mental wellness and mental applications, as documented in healthy subjects, and provided clinical benefit in the treatment of depression, anxiety, and post-traumatic disorders $[9,10,45]$.

\section{Limitation}

The small sample of the population study reduces the robustness of the results. However, the sample was homogeneous for age and Fontan type and, although the number was small, there was a significant difference before and after CRT. We did not measure pulmonary blood flow before, during and after training and thus we were unable to ascertain if CRT induced an increase in pulmonary blood flow. Furthermore, we did not assess diastolic function that plays a critical role in maintaining $\mathrm{CO}$ during exercise in Fontan patients.

\section{Conclusion}

The results of this pilot study show that a simple method of CRT based on diaphragmatic respiration is effective to improve cardiorespiratory performance, in particular significantly increasing exercise endurance time. CRT is safe, natural, easy, feasible and effective. However, larger studies are needed to confirm the results of this pilot study, also taking into account different conditions of CRT in order to optimize it. Furthermore, more studies are needed to assess the psychological benefits in terms of quality of life and self-perception.

Acknowledgements We gratefully thank Ms Elaine Laws for her precious help in the English editing of this manuscript.

\section{Compliance with Ethical Standards}

Conflict of interest All the authors have not to declare conflict of interest.

Research involving Human Participants and/or Animals The research protocol was approved by the local ethics-committee review board (Prot 0015-17 2014 P).

Informed Consent All patients or legal guardians gave informed consent, and authorized physicians to use their clinical data in accordance with Italian law.

\section{References}

1. Hoffman JI, Kaplan S, Liberthson RR (2004) Prevalence of congenital heart disease. Am Heart J 147:425-439. https://doi. org/10.1016/j.ahj.2003.05.003

2. Fontan F, Baudet E (1971) Surgical repair of tricuspid atresia. Thorax 26:240-248

3. Kukreja M, Bryant AS, Cleveland DC, Dabal R, Hingorani N, Kirklin JK (2015) Health-related quality of life in adult survivors after the Fontan operation. Semin Thorac Cardiovasc Surg 27:299. https://doi.org/10.1053/j.semtcvs.2015.08.007

4. Gewillig M (2005) The Fontan circulation. Heart 91:839-846. https://doi.org/10.3892/mmr.2016.6040

5. Sutherland N, Jones B, d'Udekem Y (2015) Should we recommend exercise after the Fontan procedure? Heart Lung Circ 24:753-768. https://doi.org/10.1016/j.hlc.2015.03.005

6. Opotowsky AR, Landzberg MJ, Earing MG, Wu FM, Triedman JK, Casey A, Ericson DA, Systrom D, Paridon SM, Rhodes J (2014) Abnormal spirometry after the Fontan procedure is common and associated with impaired aerobic capacity. Am J Physiol Heart Circ Physiol 307:H110-H117. https://doi.org/10.1152/ ajpheart.00184.2014

7. Sengupta P (2012) Health impacts of yoga and pranayama: a state-of-the-art review. Int J Prev Med 3:444-458

8. Bernardi L, Passino C, Spadacini G, Bonfichi M, Arcaini L, Malcovati L, Bandinelli G, Schneider A, Keyl C, Feil P (2007) Reduced hypoxic ventilatory response with preserved blood oxygenation in yoga trainees and Himalayan Buddhist monks at altitude: evidence of a different adaptive strategy? 
Eur J Appl Physiol 99:511-518. https://doi.org/10.1007/ s00421-006-0373-8

9. Brown RP, Gerbarg PL (2009) Yoga breathing, meditation, and longevity. Ann NY Acad Sci 1172:54-62. https://doi. org/10.1111/j.1749-6632.2009.04394.x

10. Paul-Labrador M, Polk D, Dwyer JH, Velasquez I, Nidich S, Rainforth M, Schneider R, Merz CNB (2006) Effects of a randomized controlled trial of transcendental meditation on components of the metabolic syndrome in subjects with coronary heart disease. Arch Int Med 166:1218-1224. https://doi.org/10.1001/ archinte.166.11.1218

11. Bernardi L, Spadacini G, Bellwon J, Hajric R, Roskamm H, Frey AW (1998) Effect of breathing rate on oxygen saturation and exercise performance in chronic heart failure. Lancet 351:1308-1311. https://doi.org/10.1016/S0140-6736(97)10341-5

12. Fernandes M, Cukier A, Feltrim MIZ (2011) Efficacy of diaphragmatic breathing in patients with chronic obstructive pulmonary disease. Chron Respir Dis 8:237-244. https://doi. org/10.1177/1479972311424296

13. Miller MR, Hankinson J, Brusasco V, Burgos F, Casaburi R, Coates A, Crapo R, Enright P, van der Grinten CP, Gustafsson P, Jensen R, Johnson DC, MacIntyre N, McKay R, Navajas D, Pedersen OF, Pellegrino R, Viegi G, Wanger J, ATS/ERS Task Force (2005) Standardisation of spirometry. Eur Respir J 26:319-338. https://doi.org/10.1183/09031936.05.00034805

14. Pellegrino R, Viegi G, Brusasco V, Crapo RO, Burgos F, Casaburi R, Coates A, van der Grinten CP, Gustafsson P, Hankinson J, Jensen R, Johnson DC, MacIntyre N, McKay R, Miller MR, Navajas D, Pedersen OF, Wanger J (2005) Interpretative strategies for lung function tests. Eur Respir J 26:948-968. https://doi.org/1 0.1183/09031936.05.00035205

15. Macintyre N, Crapo RO, Viegi G, Johnson DC, van der Grinten CP, Brusasco V, Burgos F, Casaburi R, Coates A, Enright P, Gustafsson P, Hankinson J, Jensen R, McKay R, Miller MR, Navajas D, Pedersen OF, Pellegrino R, Wanger J (2005) Standardization of the single-breath determination of carbon monoxide uptake in the lung. Eur Respir J 26:720-735. https://doi.org/10.1183/0903 1936.05.00034905

16. Campbell SC (1982) A comparison of the maximum voluntary ventilation with the forced expiratory volume in one second: an assessment of subject cooperation. J Occup Med 24:531-533

17. American Thoracic Society, American College of Chest Physicians (2003) ATS/ACCP statement on cardiopulmonary exercise testing. Am J Respir Crit Care Med 167: 211-277. https://doi. org/10.1164/rccm.167.2.211

18. Hill K, Jenkins SC, Philippe DL, Cecins N, Shepherd KL, Green DJ, Hillman DR, Eastwood PR (2006) High-intensity inspiratory muscle training in COPD. Eur Respir J 27:1119-1128. https://doi. org/10.1183/09031936.06.00105205

19. Shei RJ, Paris HL, Wilhite DP, Chapman RF, Mickleborough TD (2016) The role of inspiratory muscle training in the management of asthma and exercise-induced bronchoconstriction. Phys Sportsmed 26:1-8. https://doi.org/10.1080/00913847.2016.1176 546

20. Geddes EL, O'Brien K, Reid WD, Brooks D, Crowe J (2008) Inspiratory muscle training in adults with chronic obstructive pulmonary disease: an update of a systematic review. Respir Med 102:1715-1729. https://doi.org/10.1016/j.rmed.2008.07.005

21. Laoutaris I, Dritsas A, Brown MD, Manginas A, Alivizatos PA, Cokkinos DV (2004) Inspiratory muscle training using an incremental endurance test alleviates dyspnea and improves functional status in patients with chronic heart failure. Eur J Cardiovasc Prev Rehabil 11:489-496

22. Zeren M, Demir R, Yigit Z, Gurses HN (2016) Effects of inspiratory muscle training on pulmonary function, respiratory muscle strength and functional capacity in patients with atrial fibrillation: a randomized controlled trial. Clin Rehabil 30:1165-1174. https:// doi.org/10.1177/0269215515628038

23. Jung JH, Kim NS (2016) Relative activity of respiratory muscles during prescribed inspiratory muscle training in healthy people. J Phys Ther Sci 28:1046-1049. https://doi.org/10.1589/jpts.28.1046

24. Silva IS, Fregonezi GA, Dias FA, Ribeiro CT, Guerra RO, Ferreira GM (2013) Inspiratory muscle training for asthma. Cochrane Database Syst Rev 8:CD003792. https://doi. org/10.1002/14651858.CD003792.pub2

25. Zhu E, Petrof BJ, Gea J, Comtois N, Grassino AE (1997) Diaphragm muscle fiber injury after inspiratory resistive breathing. Am J Respir Crit Care Med 155:1110-1116. https://doi. org/10.1164/ajrccm.155.3.9116995

26. Anzueto A, Andrade FH, Maxwell LC, Levine SM, Lawrence RA, Gibbons WJ, Jenkinson SG (1992) Resistive breathing activates the glutathione redox cycle and impairs performance of rat diaphragm. J Appl Physiol 72:529-534

27. Penny D, Hayek Z, Redington A (1991) The effects of positive and negative extrathoracic pressure ventilation on pulmonary blood flow after the total cavopulmonary shunt procedure. Int J Cardiol 30:128-130

28. Shekerdemian LS, Bush A, Shore DF, Lincoln C, Redington AN (1997) Cardiopulmonary interactions after Fontan operations augmentation of cardiac output using negative pressure ventilation. Circulation 96:3934-3942. https://doi.org/10.1161/01. CIR.96.11.3934

29. Penny DJ, Redington AN (1991) Doppler echocardiography evaluation of pulmonary blood flow after the Fontan operation: the role of the lungs. Br Heart J 66:372-374

30. La Gerche A, Gewilling M (2010) What limits cardiac performance during exercise in normal subjects and in healthy Fontan patients? Int J Pediatr. https://doi.org/10.1155/2010/791291

31. Gewilling M, Brown SC, Eyskens B, Heying R, Ganame J, Budts W, La Gerche A, Gorenflo M (2010) The Fontan circulation: who controls cardiac output? Interact Cardiovasc Thorac Surg 10:428-433. https://doi.org/10.1510/icvts.2009.218594

32. Gewillig M, Brown SC (2016) The Fontan circulation after 45 years: update in physiology. Heart 102:1081-1086. https://doi. org/10.1136/heartjnl-2015-307467

33. Redington AN (2014) Low cardiac output due to acute right ventricular dysfunction and cardiopulmonary interactions in congenital heart disease. Pulm Circ 4:191-199. https://doi. org/10.1086/675982

34. Robbers-Visser D, Jan Ten Harkel D, Kapusta L, Strengers JL, Dalinghaus M, Meijboom FJ, Pattynama PM, Bogers AJ, Helbing WA (2008) Usefulness of cardiac magnetic resonance imaging combined with low-dose dobutamine stress to detect an abnormal ventricular stress response in children and young adults after Fontan operation at young age. Am J Cardiol 101:1657-1662. https:// doi.org/10.1016/j.amjcard.2008.01.050

35. Robbers-Visser D, Helderman F, Strengers JL, van Osch-Gevers L, Kapusta L, Pattynama PM, Bogers AJ, Krams R, Helbing WA (2008) Pulmonary artery size and function after Fontan operation at a young age. J Magn Reson Imaging 28:1101-1107. https://doi. org/10.1002/jmri.21544

36. Giardini A, Balducci A, Specchia S, Gargiulo G, Bonvicini M, Picchio FM (2008) Effect of sildenafil on haemodynamic response to exercise and exercise capacity in Fontan patients. Eur Heart J 29:1681-1687. https://doi.org/10.1093/eurheartj/ehn215

37. Shafer KM, Garcia JA, Babb TG, Fixler DE, Ayers CR, Levine BD (2012) The importance of the muscle and ventilatory blood pumps during exercise in patients without a subpulmonary ventricle (Fontan operation). J Am Coll Cardiol 60:2115-2121. https:// doi.org/10.1016/j.jacc.2012.08.970

38. Dua JS, Cooper AR, Fox KR, Stuart AG (2010) Exercise training in adults with congenital heart disease: feasibility and 
benefits. Int J Cardiol 138:196-205. https://doi.org/10.1016/j. ijcard.2009.01.038

39. Longmuir PE, Tyrrell PN, Corey M, Faulkner G, Russell JL, McCrindle BW (2013) Home-based rehabilitation enhances daily physical activity and motor skill in children who have undergone the fontan procedure. Pediatric Cardiol 34:1130-1151. https://doi. org/10.1007/s00246-012-0618-8

40. Minamisawa S, Nakazawa M, Momma K, Imai Y, Satomi G (2001) Effect of aerobic training on exercise performance in patients after the Fontan operation. Am J Cardiol 88:695-698. https://doi.org/10.1016/S0002-9149(01)01822-7

41. Moalla W, Elloumi M, Chamari K, Dupont G, Maingourd Y, Tabka Z, Ahmaidi S (2012) Training effects on peripheral muscle oxygenation and performance in children with congenital heart diseases. Appl Physiol Nutr Metab 37:621-630. https://doi. org/10.1139/h2012-036

42. Ruttenberg HD, Adams TD, Orsmond GS, Conlee RK, Fisher AG (1983) Effects of exercise training on aerobic fitness in children after open heart surgery. Pediatr Cardiol 4:19-24. https://doi. org/10.1007/BF02281001

43. Opocher F, Varnier M, Sanders SP, Tosoni A, Zaccaria M, Stellin G, Milanesi O (2005) Effects of aerobic exercise training in children after the Fontan operation. Am J Cardiol 95:150-152. https://doi.org/10.1016/j.amjcard.2004.08.085

44. Pike NA, Evangelista LS, Doering LV, Eastwood JA, Lewis AB, Child JS (2012) Quality of life, health status, and depression: comparison between adolescents and adults after the Fontan procedure with healthy counterparts. J Cardiovasc Nurs 27:539. https://doi.org/10.1016/j.amjcard.2004.08.085

45. Ray US, Pathak A, Tomer OS (2011) Hatha yoga practices: energy expenditure, respiratory changes and intensity of exercise. Evid Based Complement Alternat Med 2011:241294. https://doi. org/10.1093/ecam/neq046 